https://doi.org/10.48009/1_iis_2010_69-76

\title{
USING INFORMATION AND COMMUNICATION TECHNOLOGIES TO RENDER TRANSPARENT GOVERNANCE IN TRANSITION COUNTRIES
}

\author{
Mysore Ramaswamy, Southern University, mysore@acm.org
}

\begin{abstract}
The process of automating citizen-government interactions using information and communication technologies (ICTs) needs to be analyzed as a sociotechnical information processing system. During the process of improving the enforcement of rules via automation, which is clearly the best way to render transparency, socio-cultural factors need to be considered as they play a very important role. This is especially true in the case of post-communist transitioning countries such as Armenia where the challenges are unique. These countries are struggling with the transformation of their legacy bureaucratic and administrative processes. In addition, almost every post-Soviet country has inherited systemic corruption that is built in to the 'modus operandi' of both the public and private sectors. Without some method of categorization, assessment and modification of existing administrative processes, the formation of good policy and planning capable of leveraging the current capacity of institutions to deliver public service in a more transparent and efficient way is simply not feasible. Automating existing bureaucratic processes that are defective will not yield results. In this paper, we propose a methodology to render transparency in the governance of transition countries using information and communication technologies that goes beyond mere automating existing citizen-government interactions.
\end{abstract}

Keywords: e-Governance, e-Government, Information and Communication Technology (ICT), Post-Communist Transition, Process Restructuring.

\section{INTRODUCTION}

After the collapse of the Soviet Union, postcommunist transitioning countries such as Armenia have inherited endemic corruption. Recent innovations in information and communication technologies (ICT) have given hope to the idea that new technologies in the form of e-government systems can be used to combat corruption in the public sector. Most governments across the world desire their citizens and businesses to interface with them through electronic means for the obvious

Volume XI, No. 1, 2010 reasons of efficiency in cost-saving and effectiveness. However, whether the transparency in process and information-sharing that this presupposes is also an equally important social and cultural objective for all leaders is a less obvious assertion. As Jane Fountain states in her work, there is a certain element of the 'perversity of incentives' to acknowledge here; Kedzie calls this the "Dictator's Dilemma" in the state $[1,8]$ - where increased efficiency and political efficacy (brought about by ICTs) are positively related to each other, and negatively related to authoritarian and highly centralized control. This is especially true in transition countries where the newly emerging bureaucracies (after the Soviet collapse) are hesitant to give way to automated systems [19]. In this paper, we use the term "egovernance" in a broad sense to include a deeper understanding of the way ICTs impact the existing (and potential future) interactions between a government and its constituents. In other words, egovernance goes beyond the 'what' of an egovernment interaction that presumably delivers service to a constituent - and includes rather an analysis of the 'how' and 'why'. E-governance is distinct from e-government in that it concerns longerterm processes rather than immediate decisions. We note that one cannot improve upon something in automation that is not already rational and functional in current daily practice. The research objective of this paper is to explore the potential of ICT to render more transparency in citizen-government interactions by automating bureaucratic processes in transition countries.

The rest of this paper is organized as follows. The next section briefly describes the need for transparency in public sector bureaucracies. Postcommunist transition and its effects on system integrity are narrated in Section 3. Section 4 explains the relevance of process restructuring as a necessary precursor to automating 'government to citizen' (G2C) interactions. Conclusions and future research directions are presented in the last section.

\section{NEED FOR TRANSPARENCY}

Corruption is the misuse of public power, office or authority for private benefit. This misuse manifests in 
many ways: bribery, extortion, influence peddling, nepotism, fraud, or speed money. Petty corruption is frequently found where public servants who may be grossly underpaid depend upon small kickbacks from the public to pad their pockets and feed their families. Grand corruption involves high officials who make decisions on large public contracts for their personal benefit, or to the benefit of organized, informal groups with highly aligned self-interest as the driver of their cohesion.

In many parts of the world, a major part of the problem in dealing with public sector or government bodies is corruption. No doubt, corruption has been around since time immemorial and indeed, may well be an engrained trait of human nature; nevertheless, most governments and technologists are interested in figuring out what means may be created to combat it. In this context, 'Panoptic Vision' as proposed by Heeks [10] affords a way to analyze this critical problem. The concept of Panoptic Vision is based on the construct that sees information technology (IT) as a key enabler of management control.

Public corruption can be largely attributed to government intervention in the economy. Therefore, policies aimed at liberalization, stabilization, deregulation, and privatization can sharply reduce the opportunities for corruption [2, 3]. Where government regulations are pervasive, onerous or imprecise, and when government officials have discretion in applying them, individuals are often willing to offer bribes to officials to circumvent rules.

High levels of corruption are present where institutional mechanisms to combat corruption are weak or not used, and where a system of simple internal checks and balances does not exist. In such cases, entrenched political elite dominates and exploits economic opportunities, manipulating them in return for personal gains [12]. The significance and impact of corruption varies greatly across the world. Even though people may tolerate demands for small payments in return for official services such as the issuing of permits and licenses, they do not necessarily approve. They perceive it simply as the most painless, quick and workable way of obtaining things they want or need.

Typically, in a bureaucracy, discretion is structured by rules and standard operating procedures, and it does allow civil servants to take into consideration contextual variations and act according to other norms [20]. It has to be ensured that the uniquely human ability to act on broader societal norms is retained after ICT intervention in bureaucratic practices. The real challenge is to figure out how to modify practices that work in Western countries, so that they can work in transition countries where there is no culture of accountability and transparency in any type of constituent-government interactions.

\section{POST-COMMUNIST TRANSITION}

To get a more comprehensive perspective of the context in which the implementation of ICT for transforming governance in transition countries such as Armenia is being attempted, it is necessary to undertake a brief analysis of the period of Soviet domination. This period was characterized by a highly centralized political culture and a well defined bureaucracy driven by elite $[22,23]$. There was minimal government to citizen $(\mathrm{G} 2 \mathrm{C})$ interaction and hardly any effective mass political participation or a demand for it. All of this changed after the collapse of the Soviet Union in 1991.

A destructive legacy of Soviet rule for most successor states of the former Soviet Union has been widespread corruption. In the case of Armenia, the smooth transition of power in the early 1990s has allowed its political leaders to use corruption to consolidate firm control over the state apparatus [15, 16]. However, Armenia's economy has fared relatively well under a more centralized form of endemic corruption, albeit its concentration on largely donor driven projects.

The post-independence or transition period of Armenia started with the disruption of institutional stability and resulted in a deterioration of existing bureaucratic procedures. This has resulted in an environment of ill defined and poorly-adhered to protocols for government-to-constituent interactions [21]. The provision of clear information for the public, and moreover the public's right to it, are heretofore newly explored concepts. Before we can identify areas suitable for e-governance implementation, it is vital to ensure that a clearly defined and understandable procedure for reform is in place. Process restructuring becomes critical in this context.

Barriers to change are identified in the following four areas: Organizational Characteristics, Human Capacity, Financial Capacity, and Technical Infrastructure [19]. Organizational characteristics such as the existence of local information technology (IT) departments that address questions of automation and efficiency, and the existence of 
collaboration between IT and public relations (PR) departments which results in the availability of streamlined public information are vital to the transformation process. To a large extent this presumes that the realization of coherent public diplomacy is contingent upon a state's ability to build itself a back-end capable of effectuating its own communication systems. Data-intensive collaborations at some point involve the issue of data ownership [5, 21]. Such issues in a fledgling bureaucracy can be a potential stumbling block especially in government to government (G2G) transactions. In the same way that intelligence agencies in the United States post 9/11 discovered the major flaws in the ability of their respective vast systems to dovetail and cooperate effectively, so too do the various branches of government and their respective ministries face a challenge of interoperability. In addition, it is important to determine whether there are any institutionalized means of process review or opportunities for constituents to address their grievances. By developing the infrastructure and capacity to provide local service and service delivery, e-government can become a mechanism for spurring community involvement and thus become a catalyst for direct political interaction and/or e-participation [9, 14]. Naturally, this may be viewed with skepticism by various parts of the bureaucracy. In the context of post-communist societies, this is further exacerbated by the subservience of bureaucracy to political authority and the 'strongmen' that are frequently its human face.

The human capacity component in an institution is critical to the ability and capacity of that institution to evolve. For the purposes of this analysis, this component can be used interchangeably with the notion of social capital - even in the limited parameters of a single institution. Social capital refers to the 'stock' that is created when a group of departments or divisions develop the ability to work together and create linkages for mutually productive gain. Agents in a collaborative network, even within one institution, learn of new technologies, opportunities, challenges, and the outcome of transactions more quickly because of the density of interaction within the network [18]. Vertically organized networks, like the kind we find in the case of Armenia, tend toward characteristics that adversely affect this sort of 'mesh' learning about information processing capacity by virtue of a lack of density and 'flatness' in the nodes of the social networks that drives the political apparatus. This is an interesting point to consider because whereas complexity in networks may traditionally be associated with building up a sclerosis of sorts in an institutional body in terms of its ability to act, it can be suggested that a lack of complexity in an overly simple hierarchical network structure can equally result in a lack of clear action and effectiveness.

The financial barrier also is a critical one to the emergence of innovation and institutional transformation. This is largely about the creation of incentives for people to innovate. As it stands, the average salaries in IT departments of ministries in Armenia are quite low compared to the comparable private sector jobs, and do not create an environment conducive to innovation. The most critical element here is a lack of commitment from the top - strategic and financial - to the objectives of institutional transformation. The status quo suits the purposes of many.

Barriers posed by technical infrastructure refer to problems of depreciating equipment, lack of standardization and interoperability, an overall disregard for licenses, and an unwillingness to capitalize on telecommunication infrastructure even when it is present (i.e. as in the case of the purported 'dark' fiber running through most major government buildings). This creates an environment where change is not a priority, and where complacency becomes a rule.

In transition countries, the issues of sustainability and ownership are critical; there is a strong tendency for projects to dissolve or disappear completely after funding runs out, in part because ownership and commitment by Armenian figureheads and organizations is not always successfully assumed [19]. Moving toward institutional transparency does not necessarily serve the purpose of those who do not suffer the institutional status quo. The extent to which e-government projects could facilitate political participation is a social phenomenon that must manifest itself in the physical realm before it can extend to the virtual realm. In other words, the social reality of a political culture characterized by "unpleasant" interactions with all levels of public administration, as is the case in Armenia, can easily transcend the objectives of any IT effort to provide the opposite. To provide Online functionality that typifies an advanced polity is to present a solution thirty steps ahead of society. The technology itself can "leapfrog" various steps and standards, but should not be geared to leaping over public perceptions of "what could work here" and "what could never work here." Every society has its own answer to the question of effective ICT adoption, and in the case of transitioning countries, workable 
solutions are often hybrid; combinations of automation and social networking.

\section{SOCIO-TECHNICAL FACTORS}

Socio-technical factors pertain to exacerbated accountability dysfunctions that can occur as a consequence of automation [20]. According to Bowens [4] the major categories of dysfunctions are: Rule-obsession, Proceduralism, Rigidity, and Scapegoating.

Rule-obsession or Output-obsession refers to the focus on outcomes over process. Proceduralism refers to increased emphasis on procedures to avoid responsibility and accountability. Strict adherence to procedures cam render the bureaucracy to lose the ability to balance procedures with public values. Relying heavily on encoded computer procedures can undermine the effectiveness of public sector organizations.

The ability to take contextual variations into account is affected by the encoding of procedures which actually results in encoding rigidity. After developing a system, the embedded rigidity can make it difficult to modify as part of organizational learning. As a result of the introduction of ICTs in the public sector, there has been a displacement of accountability from bureaucrat to software engineer. When things go wrong, the tendency is to use the computer as a scapegoat.

The degree of automation can vary across a wide range. Smith [20] states a scale of nine degrees of automation starting from the first level where the computer offers no assistance to the ninth level where the computer decides everything. In between these extremes, there are several levels where a varying degree human-computer interaction occurs. The appropriate level of ICT intervention depends on the particular interaction that has to be automated.

The need for transparency and accountability calls for automated systems. But in transition countries, where there is no culture of established bureaucracy, there is also a concomitant need for accommodating sociocultural factors. An analysis of the existing bureaucratic practices in transition countries indicates two areas that need attention. The first pertains to the availability of information regarding governmental procedures to the general public. Acquiring such information is quite simple in most western societies. But in the post-communist context, government officials, especially at the lower levels, make it harder for the public to execute these transactions so their reliance on the officials who "sell" this information and "facilitate" the required transaction is not diminished. The roots of public sector corruption are found in such opportunities. The second area of concern is the convoluted way in which governmental procedures in general are laid out. During the Soviet era, several layers of authority were embedded in the bureaucratic system. After the fall of the Communist regime, no congruous system emerged to replace it. This gave an opportunity for government officials to use the system to their advantage. Clearly, the simplification and clarification of procedures has not been their priority [19]. This elucidates the point that process restructuring should also accompany a concomitant improvement in the work and incentive conditions of the government employees delivering public service. This necessitates the emergence of an environment in which all participants have a share in the benefits of modern technology.

All segments of society have to be included in egovernance if it is to be an effective tool in combating corruption and rendering a more transparent bureaucracy. This is sometimes referred to as e-inclusion. In order to build a more inclusive ICT-implemented society, we must ask the following questions:

- How can we make the public sector bureaucracy truly citizen-centric?

- Do we have objectives that are correct and realistic?

- How well are we achieving these objectives fully and cost effectively?

- Are these objectives jointly determined and agreed upon by the citizens and the government agencies?

A critical component in the multilayered process of rendering transparency pertains to the availability of digital content that users can access. User interactions with digital or electronic means have been grouped in a number of ways $[11,16]$. In the present analysis, it will be useful to categorize them in the following way: information services, communication services, and transaction services. An inclusive and accountable bureaucracy has to provide more useful digital interactions to a larger segment of society, especially in the third category of transaction services $[6,7]$.

There is little apparent understanding as to where the main impact of ICTs will be, and this is manifested by an obvious collective misunderstanding as to what e-government should accomplish. The development of ICTs in government - to support both back-end 
and front-end systems - should come not only from the united front of a coordinated and coherent donor stream, but in conjunction with genuine efforts to promote organic (as opposed to transplanted) growth strategies [19]. Anything less will result in a continued flow of ineffective funding that misses the mark in terms of meeting the objectives of true institutional transformation, which in large part - and with few exceptions - describes the status quo in Armenia today.

\section{PROCESS RESTRUCTURING}

Clearly, ICT can play a critical role in bringing transparency in government to citizen (G2C) interactions. Automating existing bureaucratic procedures, per se, will not yield transparency. As Michael Hammer, a well-known business consultant who championed business process reengineering, wrote an article in Harvard Business Review titled "Don't Automate, Obliterate." He stresses the importance of simplifying processes, eliminating non-value added tasks, and innovating to improve speed, quality, and service. No meaningful improvements can be expected by simply automating the existing inefficient processes. This is especially true in the case of a transition country like Armenia. In this section, we provide a typical interaction and explain how it can be restructured. Our case study for task analysis and process restructuring pertains to a G2C interaction, viz., acquiring registration for a car.

Some of the above concerns can be addressed by developing a framework that takes into consideration the resistance to change as well as the processing complexity of various transactions. As indicated in Appendix I, our framework is a cube made up of the following three sides: entity type represented on the length (x-axis), processing complexity on the height (z-axis), and resistance to change on the width (yaxis). These parameters are particularly relevant in transition countries where socio-technical factors which manifest as resistance to change have to be taken into account.

In this Process Restructuring Framework, constituent-to-government interactions are categorized into three groups: government-togovernment (G2G), government-to-business (G2B), and government-to-citizen (G2C). This categorization is useful for analyzing differences in the types of information needs typically necessary for the successful execution of specific types of service delivery. The entity type is represented on the $\mathrm{x}$-axis.

Volume XI, No. 1, 2010
Processing complexity is represented on the z-axis. The processing complexity of an interaction is a function of the information available as to how to execute that task, as indicated in Appendix II. Focusing on the information required for processing a transaction, we can combine relevance, accuracy and precision, and define 'correctness' as an attribute that refers to the accuracy and relevance of the information provided, while adding in some way to the successful execution of a task. In addition to 'correctness', we find that the following three attributes are necessary and sufficient to capture its utility: 'completeness', 'clarity', and 'ease of accessibility'. The adequacy of available information to process a task is captured by the term 'completeness'. 'Clarity' is the expectation that the information provided is in a form and language that is easy to understand. 'Ease of accessibility' indicates the ease with which people who need it can find and access that information. Each attribute is measured in turn on the binary basis of values set between 0 and 1,0 referring to the absence of these attributes, and 1 referring to their presence.

The third aspect of this framework refers to an important socio-technical factor, 'Resistance to Change'. The level of resistance in government to restructuring, and the subsequent automation of bureaucratic procedures already in place is an important factor to be addressed to while planning ICT intervention. This dimension of resistance to change is represented on the y-axis. The range of this aspect is divided into three simple parts: low (L), medium $(\mathrm{M})$ and high $(\mathrm{H})$. Thus, the interactions towards the top of this Process Restructuring Cube have a higher resistance to restructuring. Defining these ranges for the axes in this way enables the division of the Process Restructuring Framework into 27 sub-cubes. Consider a 'government-to-citizen' interaction of 'processing complexity' $\beta$, and of 'resistance to change' of medium range $(C, \beta, M)$. Before automating this interaction, we need to transform this to an interaction of lesser processing complexity $\alpha$.

This framework provides a means of evaluating an extensive (if not comprehensive) series of government-constituent interactions. Depending upon the value of the parameters of the given transaction, we are able to make inferences on the potential of that transaction for potential of ICT intervention. This naturally opens up a wide arena of analysis, particularly for others who wish to specialize and focus specifically on the dynamics and characteristics of specific interactions where ICT intervention is useful. 
We propose a two-stage process for implementing ICT tools to render transparency in public sector bureaucracy. In the first stage, we examine the existing range of government-constituent interactions. This is indeed very large as evidenced by the three stakeholder groups of constituents (citizen, business, and government). The gamut of interactions is also very diverse. It is critical that these interactions are properly restructured, before being automated. During the stage of restructuring, the Process Restructuring Framework can be used to prioritize the restructuring process. A task that is at a distance from the $\mathrm{x}$-axis (higher complexity as well as more resistance to change) requires far more attention than a process that is less complex and that is less resistant to change. In the context of transition countries, we need to choose those interactions that are have less process complexity and has more popular acceptance (less resistance to change) first, and then take on more complex interactions.

The second stage consists of the actual implementation of ICT tools into the public sector bureaucracy. Rendering accountability and transparency has to be an evolutionary process, characterized by both top down and bottom up 'buy in', so that it can be accepted with minimum resistance by the bureaucracy as a whole. It is more pragmatic to start with smaller steps of automated procedures that are less controversial (i.e., as in the case of the very successful e-visa in Armenia, launched by the Ministry of Foreign Affairs) and succeed, than to be more ambitious and fail at the start. Prioritization of transactions can be done in the G2C part of the Process Restructuring Cube as these activities have the most impact on reducing public sector corruption.

The main objective of restructuring various processes before transforming them into digital interactions is to improve the effectiveness of bureaucracy as a system and make it more transparent. It is to be noted that placing an IT layer over and automating a faulty bureaucratic system may yield a more efficient system, but will certainly not be one desired by or responsive to its core constituents, and will not help in any way to combat corruption or perceptions of it.

\section{CONCLUSION}

The basic building blocks of ICT implementation in public sector bureaucracy consist of digitized versions of interactions between the government and its constituents. In this paper, we have presented a framework that can, in one small way, identify and

Volume XI, No. 1, 2010 categorize dealings of the public with the types of government structures prevalent in post-Soviet transitioning states. Changing the bureaucratic methods and human attitudes of those 'running the system' in post-soviet transition countries is doubly challenging. These countries suffered the first shock during the total collapse of public administration when the Soviet Union disintegrated. Now, the nascent bureaucracy considers automating G2C interactions as a second shock. Restructuring the bureaucratic procedures and then automating them in a systematic way as suggested in this paper affords a practical approach to render transparency and accountability to public sector.

Future work in this area focuses on developing a comprehensive framework that will enable policy makers and researchers to point out the potential priority areas that need to be automated first to render accountability and transparency, and also yield a realistic estimate of resources needed to achieve such transformation. In addition, such an approach will also help in giving a better insight into process restructuring.

\section{REFERENCES}

1. Allison, Juliann Emmons. (2002) Technology, Development, and Democracy: International Conflict and Cooperation in the Information Age. Albany: State University of New York Press.

2. Anechiarico, F. and Jacobs, J. and B. (1994)

"Visions of Corruption Control and the Evolution of American Public Administration," Public Administration Review, Vol. 54, No. 5, pp. 465-473.

3. Bardhan, Pranab. (1997) "Corruption and Development: A Review of Issues," Journal of Economic Literature, Vol. 35 pp. 1320-1346.

4. Bowens, M. (2005) "Public Accountability," in Ferlie, E.. J. Lawrence, E. Lynn, and C. Pollitt (eds.), The Oxford Handbook of Public Management, Oxford University Press, pp. 182-208.. 5. Bremmer, Ian and Cory Walt. (1997) “Armenia's New Autocrats," Journal of Democracy, No. 8 (July), pp. 77-91.

6. Carbo, T. and Williams, J. (2004). Models and Metrics for Evaluating Local Electronic Government Systems and Services. The Electronic Journal of Electronic Government, Vol. 2, No. 1, pp. 99-106.

7. Carbo, T. and Williams, J. G. (2004). "Some Determinants of User Perceptions of Information Quality on the World Wide Web," Electronic Journal of e-Government, Vol. 2, No. 2 pp. 94-105. 
8. Fountain, Jane E. (2001) Building the Virtual State: Information Technology and Institutional Change. Washington, DC: Brookings Institution Press.

9. Heeks, R (2003). "Causes of eGovernment Success and Failure: Design Reality Gap Model," http://www.e-devexchange.org/ eGov/ causegap.htm

10. Heeks, R (1998). "Information Systems for Public Management: Information Technology, and Public Sector Corruption," Working Paper No. 4, Manchester: IDPM-University of Manchester.

11. Homburg, V. and Bekkers, V. (2002) "The Back-Office of E-Government," Proceedings of the $35^{\text {th }}$ Hawaii International Conference on Information Systems, (9 pages).

12. Karklins, Rasma. (2005) The System Made me do it: Corruption in Post-Communist Societies. Armonk, NY: M. E. Sharpe.

13. Kuzmin, A. (2003). "The Two Dimensions of e-Government: Potential and Use," www. procesconsulting. ru/ doc/ Two_dimensions_of_eGovernment.pdf

14. Moore, M. (1997) Creating Public Value: Strategic Management in Government. Cambridge, MA: Harvard University Press.

15. Olson, M. (2000) Power and Prosperity: Outgrowing Communist and Capitalist Dictatorships. New York, NY: Basic Books.

16. Ramasoota, P. (1998). "Information Technology and Bureaucratic Surveillance," Information Technology for Development, Vol. 8, No. 1, pp. 51-64.
17. Ramaswamy, M. and Selian, A. (2007). eGovernment in Transition Countries: Prospects and Challenges, Proceedings of the $40^{\text {th }}$ Hawaii International Conference on Information Systems, (10 pages).

18. Scholl, H. J. (2003) "E-Government: A Special Case of ICT-enabled Business Process Change," Proceedings of the $36^{\text {th }}$ Hawaii International Conference on System Sciences, (12 pages).

19. Selian, A. (2005) "The Use of ICT as Tools for Institutional Transformation in Armenia," Armenian Journal of Public Policy, Vol. 2, No. 1, pp. 91-111.

20. Smith, M. L., et al. (2010) "Automating the Public Sector and Organizing Accountabilities," Communications of the Association for Information Systems, Vol. 26, Article 1.

21. Stefes, C. H. (2006) Understanding Post Soviet Transitions: Corruption, Collusion, Clientelism. New York, NY: Palgrave Macmillan.

22. Wang, H. and J. Rosenau. (2001). "Transparency International and Corruption as an Issue of Global Governance," Global Governance, No. 7, pp. 25-49.

23. Wimmer, M. R. et al (2001) "Electronic Business Invading the Public Sector: Considerations on Change and Design" Proceedings of the $34^{\text {th }}$ Hawaii International Conference on System Sciences, (10 pages). 


\section{APPENDIX I. Process Restructuring Framework}

Entity Type Key:

G2G: G

G2B: B

G2C: C

Complexity Key:

$0 \rightarrow$.33: $\alpha$

$.33 \rightarrow .66: \beta$

$.66 \rightarrow 1: \mathrm{\gamma}$

\section{Resistance to} Change Key:

Low: L

Medium: M

High: $\mathrm{H}$

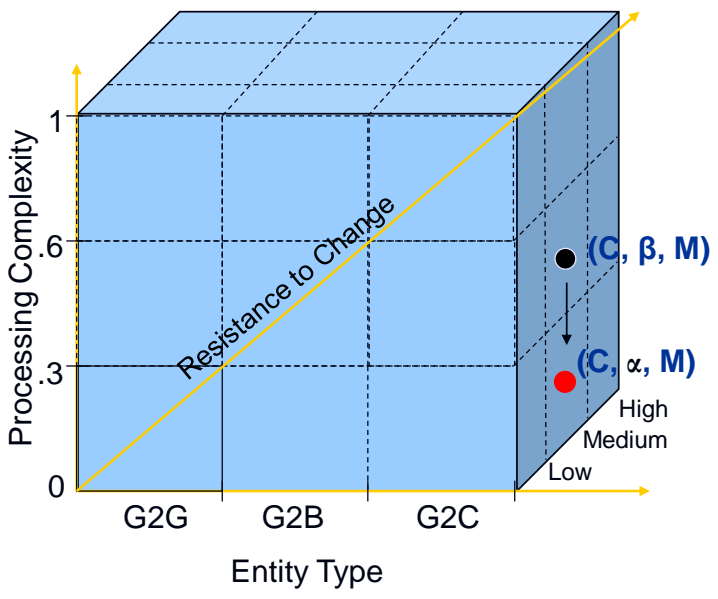

APPENDIX II. Complexity Analysis

\section{Assumptions}

- Task complexity is $=$ 1 if correctness is 0 , irrespective of other dimensions

- Other dimensions are weighted according to their importance to the completion of the task

$\mathrm{C}_{\mathrm{S}}=f(\mathrm{~A}, \mathrm{~B}, \mathrm{C}, \mathrm{D})$
\begin{tabular}{|c|c|c|c|c|}
\hline $\begin{array}{c}\text { A } \\
\text { Correctness }\end{array}$ & $\begin{array}{c}\text { B } \\
\text { Completeness }\end{array}$ & $\begin{array}{c}\text { C } \\
\text { Clarity }\end{array}$ & $\begin{array}{c}\text { D } \\
\text { Ease of Access }\end{array}$ & $\begin{array}{c}\text { SubTask } \\
\text { Complexity }\end{array}$ \\
\hline 0 & 0 & 0 & 0 & 1 \\
1 & 0 & 0 & 0 & .75 \\
1 & 0 & 0 & 1 & .50 \\
1 & 0 & 1 & 0 & .50 \\
1 & 1 & 0 & 0 & .50 \\
1 & 1 & 0 & 1 & .25 \\
1 & 0 & 1 & 1 & .25 \\
1 & 1 & 1 & 0 & .25 \\
1 & 1 & 1 & 1 & 0 \\
\hline
\end{tabular}

